\title{
Extrathoracic Communication of Persistent Pulmonary Tuberculous Pneumatocele
}

\author{
Sung-Jin Hong ${ }^{a}$ Sena Hwang ${ }^{c}$ Sung Ho Hwang ${ }^{b}$ Dae Yeon Kim ${ }^{a}$ Suck-Jun Kong ${ }^{a}$ \\ Departments of a Internal Medicine and ${ }^{\mathrm{b}}$ Radiology, Mokpo National Hospital, Mokpo, and \\ 'Department of Internal Medicine, Yonsei University College of Medicine, Seoul, South Korea
}

A 33-year-old man presented with a productive cough. Four years earlier, we had treated the same patient for pulmonary multidrug-resistant tuberculosis for only 12 months, after which he became lost to follow-up. The patient's sputum smears were positive for acid fast bacilli. Chest radiography showed apical cavitary consolidation in the right upper lobe, extensive opacification due to pleural effusion in the left lower lobe and a large pneuma- tocele in the left upper lobe. A linear air pocket in the soft tissue of the left upper hemithorax was also noted (fig. 1c). $\mathrm{CT}$ revealed a $15 \times 6 \mathrm{~cm}$ cavitary lesion in the left upper lobe extending and communicating with the chest wall through a fistulous tract without pneumothorax or mediastinal emphysema (fig. 2). The subcutaneous air pocket had been noted on the patient's examination 4 years prior (fig. 1a). It had gradually decreased with antituber-

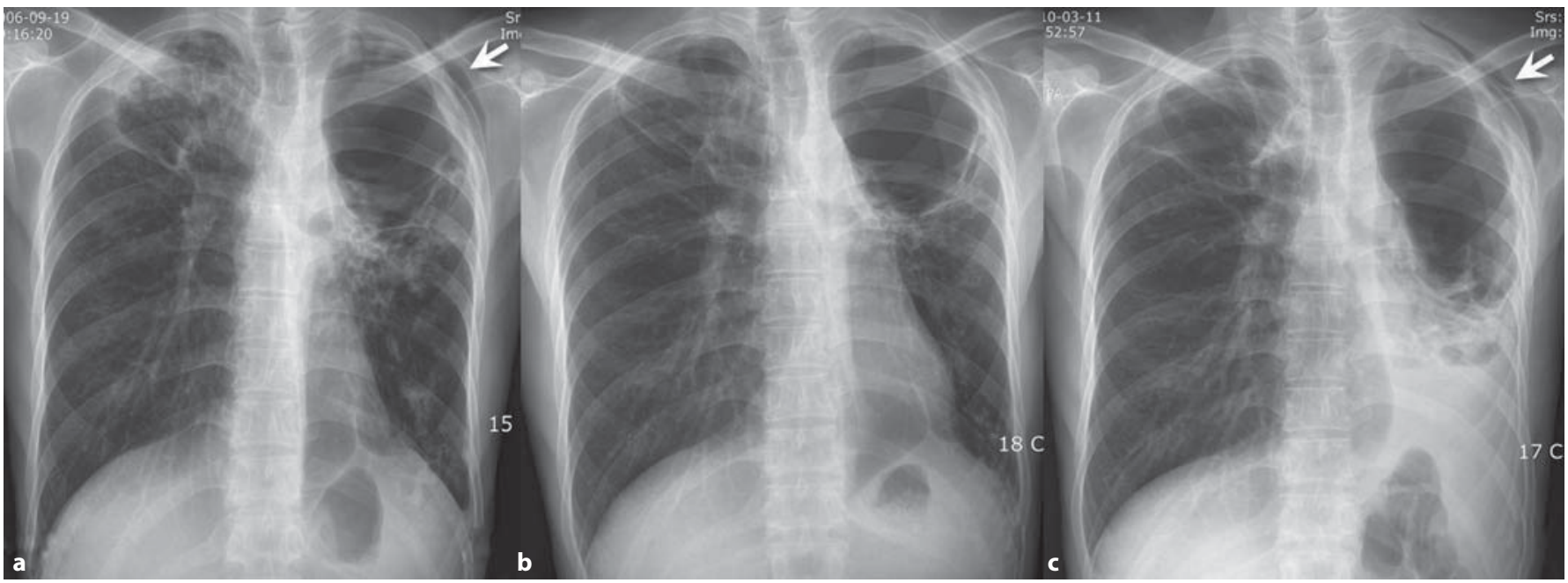

Fig. 1. a Chest radiograph showing a large pneumatocele in the left upper lobe and a linear air pocket in the soft tissue of the left upper hemithorax (arrow) upon his initial visit (4 years prior to second presentation). b After 12 months of antitubercu- lous therapy, the air pocket had nearly disappeared, but the pneumatocele persisted. c When the patient presented a second time, the air pocket had reappeared and the pneumatocele was also seen.

\section{KARGER}

Fax +4161306 1234

E-Mail karger@karger.ch

www.karger.com
(C) 2010 S. Karger AG, Basel

$0025-7931 / 11 / 0813-0247 \$ 38.00 / 0$

Accessible online at:

www.karger.com/res
Sung-Jin Hong

Department of Internal Medicine, Mokpo National Hospital

1-71 Shinji Maeul

Mokpo 530-828 (South Korea)

Tel. +82 61280 1114, Fax +82 61283 2578, E-Mail sungjhong@ naver.com 


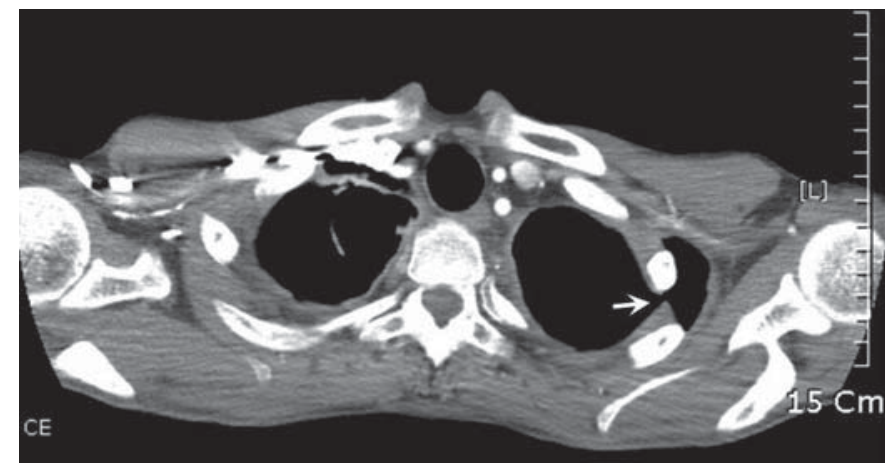

Fig. 2. CT image revealing pneumatocele and subcutaneous air pocket. These two spaces communicated with each other through a fistulous tract (arrow).

culous treatment and nearly disappeared after 12 months of treatment (fig. 1b). In addition to the air pocket, the large pneumatocele in the left upper lobe had also been noted 4 years prior, but it had persisted despite treatment. We considered a left pneumonectomy to improve his chances of cure and prevent complications related to persistent large pneumatoceles, such as cardiorespiratory compromise, but the patient refused. He was restarted on second-line antituberculous treatment.
Tuberculous pneumatocele is uncommon and extrathoracic involvement is exceedingly rare $[1,2]$. In our patient, transpleural fistulous communication as visualized on CT scan was responsible for the extrathoracic involvement. We believe that pleural inflammation sealed both visceral and parietal pleura and increased intrapulmonary pressure, causing rupture at a pre-existing weak point allowing escape of air without involving the pleural cavity. The subcutaneous air pocket gradually decreased in size with antituberculous treatment and increased after cessation of treatment. The persistence of pulmonary pneumatocele over a period of 4 years has not been previously reported. Our patient's persistent pneumatocele may be explained by his prior incomplete treatment for multidrug-resistant tuberculosis. Thus, extrathoracic communication of tuberculous pneumatoceles can persist after incomplete treatment of tuberculosis, especially in patients with multidrug-resistant tuberculosis.

\footnotetext{
References $\quad D_{1}$ Quigley MJ, Fraser RS: Pulmonary pneumatocele: pathology and pathogenesis. AJR Am J Roentgenol 1988;150:1275-1277.

-2 Duttaroy DD, Jagtap J, Bansal U, Duttaroy B: Tuberculous pulmonary pneumatocele communicating extrathoracically. Thorax 2006; 61:738.
} 